\title{
LA MÚSICA, PERO TAMBIÉN MÚSICA: NUEVOS CÁNONES DE TOMÁS DE IRIARTE
}

\section{THE MUSIC, BUT MUSIC TOO: NEW CANONS BY TOMÁS DE IRIARTE}

\author{
Victoriano J. Pérez Mancilla \\ Universidad de Granada \\ viperez@ugr.es \\ ORCID iD: orcid.org/0000-0002-5960-6758
}

\begin{abstract}
Resumen
Tomás de Iriarte ha pasado a la historia como uno de los escritores más relevantes del neoclasicismo español, pero también por haber contribuido decididamente a la teoría del arte de los sonidos en el siglo XVIII con su poema didáctico La música. No obstante, también fue un intérprete aficionado de instrumentos como la viola y desarrolló una significativa actividad como compositor, aunque hasta el momento solo se conozca la música de su melólogo Guzmán el Bueno y una colección de diecisiete cánones, estos últimos conservados en una fuente del Conservatorio Superior de Música de Madrid publicada hace solo una década. Sin embargo, en este trabajo de investigación damos a conocer otra colección de cánones más antigua y completa que la citada, inédita hasta la fecha, que contiene una veintena más de obras distintas a las recogidas en la fuente madrileña.
\end{abstract}

\author{
Palabras clave \\ voces. \\ Bajo, cánones, catalogación, compositor, intérprete, Iriarte,
}

Tomás de Iriarte (1750-1791) fue uno de los escritores más importantes de la literatura neoclásica española, cuya carrera comenzó traduciendo al español obras de teatro francesas. No obstante, pronto empezó a publicar su propia producción con comedias como Hacer que hacemos ${ }^{1}$, de 1770 , aunque su aportación más reconocida a la historia de la literatura son sus Fábulas Literarias, de 1782. Curiosamente, Iriarte introdujo en

\footnotetext{
1 IRIARTE NIEVES-RAVELO (1770).
}

(C) 2018 CSIC. Este es un artículo de acceso abierto distribuido bajo los términos de una licencia de uso y distribución Creative Commons Attribution 4.0 International (CC BY 4.0).

Cómo citar este artículo/Citation: Pérez Mancilla, V. (2018). La Música, pero también música: Nuevos cánones de Tomás de Iriarte. Anuario Musical, 73: 193-200. doi: http://dx.doi.org/10.3989/redc.2018.73.13

\begin{abstract}
Tomás de Iriarte has gone down in history as one of the most important Spanish Neoclassicism writers. Beyond, he contributed to the theory of sound art in the 18th century with his didactic poem La música. However, Iriarte was also an amateur player of instruments like the viola and he had important activity as a composer. In spite of this, until now we only know the music of his melologist Guzmán el Bueno and a collection of seventeen canons. These canons are preserved in a source of the Superior Music Conservatory of Madrid and they have been published only a decade ago. Nevertheless, in this research, we present another oldest and most complete canons collection than the aforementioned. It is unpublished to date and it contains more than twenty works different from those collected in the Madrid source.
\end{abstract}

\section{Key words}

Bass, canons, cataloging, composer, player, Iriarte, voices.

ellas el elemento musical, al igual que en mucha de su producción literaria, con fábulas como la de "La campana y el esquilón", "El burro flautista" o "La música de los animales"'. No en vano, era un gran aficionado al arte de los sonidos y tenía cierta formación en el mismo, lo que le llevó a escribir en 1779 el poema didáctico La música ${ }^{3}$. Esta obra, dividida en cinco cantos y dentro de la corriente ilustrada, mereció la alabanza del pro- 
pio Pietro Metastasio, siendo traducida a varios idiomas por su enorme acogida a nivel europeo ${ }^{4}$.

A pesar de la importancia de su poema didáctico para la teoría musical española, la faceta de Tomás de Iriarte que más interesa a este trabajo es la de músico. Sobre ella se ha señalado en varias ocasiones que estudió con Antonio Rodríguez de Hita, noticia que emana del elogio biográfico que tras el fallecimiento de Iriarte escribió su amigo Carlos Pignatelli, recogiendo que "llegó por fin a saber la composicion y a tocar de repente el violin, y la viola sólo por observacion y practica, y después con el auxilio de alguna instruccion que recibio de su amigo el maestro de capilla de la Encarnacion don Antonio Rodriguez de Hita"5. Cabe señalar que Carlos Pignatelli era hermano de María Manuela Pignatelli, duquesa de Villahermosa, quien organizó en su casa numerosos conciertos o "academias armónicas" como se conocían en la época, además de ser alumna de música de Iriarte ${ }^{6}$.

Respecto a la interpretación, el propio Iriarte afirmaba tocar distintos instrumentos en esas "academias armónicas". Así, en su Epístola VII, del 8 de enero de 1776, recoge cómo:

Noches hay en que se hallan congregados veinte y acaso más aficionados, que su parte ejecutan de repente. Mi manejo no es mucho ni muy poco, y entre ellos logra así lugar decente, pues, cuando no violín, la viola toco, la viola que algún día en nuestras academias de armonía tú solías tocar por instinto, de la cual yo quedé por substituto [sic]. Gozamos un depósito abundante de la moderna música alemana, que en la parte sinfónica es constante que arrebató la palma a la italiana. Si alguno al contrapunto se dedica, y cualquier obra suya manifiesta, la aficionada orquesta se la prueba, examina y califica; y aún con benignidad los circunstantes oyen mis sinfonías concertantes?

Con este texto se pone de relieve la actividad de Iriarte como intérprete de violín y viola e, incluso, como compositor de "sinfonías concertantes", aunque hasta el momento no se conozca ninguna de ellas. En cuanto a la interpretación también resulta muy significativo que en una carta que escribe Iriarte el 22 de agosto de 1781 a su amigo Manuel Delatila, marqués de Manca, contando el viaje que está haciendo por localidades del centro peninsular, recoge cómo en la villa guadalajareña de Aranzueque "para pasar el tiempo hasta mediodía, me fui a tocar el órgano de la iglesia, que no es malo. El sacristán quedó tan prendado de mi sobresaliente habilidad, que me envió de regalo unos peces que había pescado aquella mañana" ; por tanto, a la capacidad para tocar el violín y la viola hay que añadir también la de organista. Respecto al marqués de Manca, cabe señalar que, al igual que otros nobles como la ya citada duquesa de Villahermosa, organizaba conciertos en su casa de la madrileña carrera de San Francisco: incluso, tanto el marqués como Iriarte

\footnotetext{
4 COTARELO Y MORI (1897): 205-207.

5 Citado en AGUIRRE (1916): 222.

6 SUBIRÁ PUIG (1949): vol. I, 121.

7 Citado en MARTÍN MORENO (1985): 293-294.

8 Citado en COTARELO Y MORI (1897): 469.
}

intervenían en esos conciertos tocando el violín y el violín y la viola respectivamente ${ }^{9}$.

En la misma carta del 22 de agosto de 1781 Iriarte recoge que se alojó en el convento franciscano de Nuestra Señora de la Salceda, entre las localidades también guadalajareñas de Tendilla y Peñalver, donde ${ }^{10}$ :

desvelado y oyendo tocar a maitines, me vino en deseo irme al coro ya que no dormía, y hacer mis observaciones musicales sobre el canto llano [...]. Pero la cosa era imposible; porque los Padres, según la estrecha clausura que allí observan, tienen cerrada toda comunicación de la hospedería con lo interior del convento ${ }^{11}$.

De hecho, el conocimiento de Iriarte del canto llano debía ser significativo, porque incluso en 1786 es nombrado censor de una obra sobre canto gregoriano escrita por el tenor de la Capilla Real, Vicente Pérez Martínez ${ }^{12}$.

Como músico cabe destacar que ha llegado hasta nosotros una importante obra compuesta por Tomás de Iriarte en 1790, durante su estancia en Sanlúcar de Barrameda para mejorar de la gota que padecía ${ }^{13}$. Se trata del melólogo Guzmán el Bueno, cuyo texto también era de Iriarte, inspirado en el Pygmalion de Rousseau y en la línea del Hannibal de González del Castillo ${ }^{14}$. Recordaremos que el melólogo, tal y como lo había creado Rousseau, consistía en una obra teatral monologada, con introducción de música en determinados momentos en los que el actor permanecía en silencio. En concreto, Guzmán el Bueno consta de diez números musicales, con una plantilla de flautas, clarinetes, fagotes, trompas, violines primeros y segundos, violas y violoncellos ${ }^{15}$.

En cuanto a las composiciones, ya se ha recogido que el propio Iriarte señalaba que componía sinfonías, aunque estas no han llegado hasta nosotros o, esperemos, aún no han salido a la luz, al igual que algunos cuartetos ${ }^{16}$. Sin embargo, conocemos un canon de Iriarte gracias a Hilarión Eslava, quien lo incluyó en uno de sus libros para el aprendizaje de la composición. Esta obra la cita como ejemplo de "canon de sociedad", que:

se llama al que contiene una frase ó periodo melódico, repetido por cada una de las voces alternativamente y seguido de contrapuntos que sirven de acompañamiento a aquel, formando un canon perpetuo.

9 Ibidem: 475 y 554 .

10 Sobre este convento véase FERNÁNDEZ MADRID Y GÓMEZ LORENTE (1992): 431-444.

11 COTARELO Y MORI (1897): 470.

12 El informe como censor puede consultarse en SUÁREZ-PAJARES (2000): 473-474; la obra debió ser la de PÉREZ MARTÍNEZ (1799).

13 COTARELO Y MORI (1897): 384.

14 ROUSSEAU (1771); GONZÁLEZ DEL CASTILLO (1791).

15 La música de Guzmán el Bueno se conserva en la Biblioteca Histórica Municipal del Ayuntamiento de Madrid, con la signatura "Música 14-2". Véase la transcripción de la obra, tanto de la parte musical como literaria, en IRIARTE NIEVES-RAVELO (1999).

16 SUÁREZ-PAJARES (2000): 474. 
Para que se comprenda claramente lo que es canon de sociedad, bastará presentar uno muy sencillo, que obtuvo en el siglo pasado gran popularidad entre los aficionados, y que dicen ser compuesto por el distinguido literato D. Tomas de Yriarte, autor del poema La música. Este canon á 3 voces iguales consta de una frase principal que la componen los 8 compases $1^{\text {os }}$., y de dos contrapuntos $1^{\circ}$. y $2^{\circ}$. que cada uno de ellos tiene 8 compases. El orden de ejecucion es el siguiente: la voz $1^{\mathrm{a}}$. dice sola la frase principal, y mientras ella ejecuta el $1^{\mathrm{r}}$. contrapunto, la $2^{\mathrm{a}}$. voz entra cantando dicha frase principal: mientras la voz $1^{\mathrm{a}}$. dice el $2^{\mathrm{a}}$. contrapunto y la $2^{\mathrm{a}}$. el $1^{\mathrm{o}}$. entra la $3^{\mathrm{a}}$. como lo han hecho antes la $1^{\mathrm{a}}$. y $2^{\mathrm{a}}$. etc., volbiendo [sic] despues cada una de ellas desde el fin al principio, segun se observa en los canones perpetuos ${ }^{17}$.

A continuación Hilarión Eslava introduce el canon, es decir, con la frase principal y los dos contrapuntos de la misma. Pero esta no es la única fuente que ha llegado hasta nosotros con dicha obra, ya que en el Conservatorio Superior de Música de Madrid se conserva una colección de cánones de Tomás de Iriarte, entre ellos el que Eslava recoge en su tratado. Estos fueron transcritos en marzo de 2008 por el profesor Víctor Pliego, quien tuvo el acierto de darlos a conocer publicándolos un año más tarde ${ }^{18}$. Sin embargo, esta publicación no inserta un estudio preliminar y, además, muchas de las obras se transcriben transportadas o sin el bajo con el que cuentan en el documento original. Además, cuando se inserta este bajo se le adapta el texto de la parte vocal o una sección del mismo, llegando incluso a modificar la música casi totalmente. En definitiva, la transcripción del profesor Pliego tiene un claro carácter práctico, siendo este el gran mérito de la publicación junto a la importancia de sacar a la luz un repertorio desconocido hasta el momento.

En concreto, la fuente original forma parte de un volumen manuscrito en papel con signatura M-RCSM Roda 355 y obras de diverso género, formato y autor, es decir, que se trata de una recopilación para permitir una mejor conservación de las mismas. La sección de los cánones, con signatura M-RCSM Roda 355 (2), consta de ocho folios con un tamaño ligeramente superior al A4, a los que se añaden otros cuatro en tamaño algo mayor que la cuartilla, es decir, al A5.

Entre todos presentan una numeración que va del folio 166 al 181, que no corresponde al volumen en el que se encuentran, demostrando que anteriormente formaban parte de otra colección. Además, los primeros ocho folios de formato semejante al A4 (del 166 al 173), se numeran solo por una cara, mientras que los cuatro restantes parecidos al A5 (del 174 al 181) presentan numeración tanto en la parte recta como en la vuelta. El documento empieza con una portada donde se puede leer "Canones de Dn. Tomas de Yriarte", recogiendo después una colección de nueve "Canones a tres voces" (fols. 167r-169v), otros ocho "Canones a quatro voces" (fols. 170r-172v) y tres "Canones de otros autores" (fols.

17 ESLAVA Y ELIZONDO (1864): 75-76.

18 IRIARTE NIEVES-RAVELO (2008); IRIARTE NIEVESRAVELO (2009). 172v-173r), sección esta última que continúa en los folios del formato parecido al A5 con grafía también distinta (fols. 174-181).

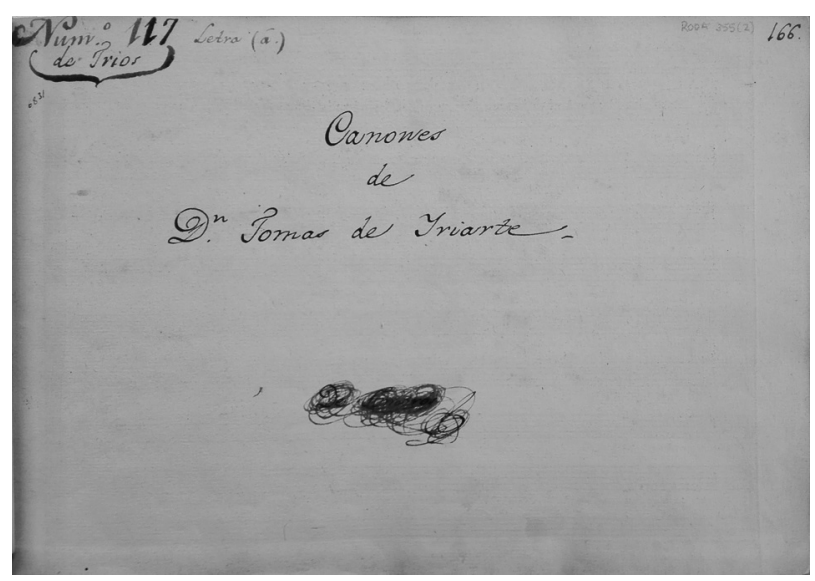

Fig. 1: Cánones de Tomás de Iriarte. Biblioteca del Conservatorio Superior de Música de Madrid. Signatura M-RCSM Roda 355 (2), fol. 166 r.

Los cánones de Iriarte de esta fuente, que son los que interesan para nuestro estudio, están formados por la frase principal y sus contrapuntos en clave de Sol en $2^{\mathrm{a}}$, la mayoría de veces situados en líneas diferentes de pentagrama para que coincidan los compases que van formando la polifonía -a excepción de algunos muy cortos en los que los distintos elementos aparecen seguidos-. Además, esta colección se caracteriza porque todos los cánones presentan al final una parte de bajo en clave de $\mathrm{Fa}$ en $4^{\mathrm{a}}$ sin letra, con grandes saltos, valores largos en ocasiones y amplia tesitura, lo que parece indicar que se trate de bajos instrumentales. Como excepciones hay que citar el canon de letra El claro arroyuelo, en el fol. 168r, que recoge el nombre de las notas; y el canon de texto Válgame Nuestra Señora, en el folio $172 \mathrm{v}$, puesto que señala la palabra "Bajo" seguida de la clave, la armadura y el compás, pero las notas no se han recogido.

En definitiva, esta fuente del Conservatorio Superior de Música de Madrid es importante por contener nada menos que diecisiete cánones de Tomás de Iriarte, de quien hasta que el profesor Víctor Pliego los sacó a la luz solo se conocía el que Eslava insertó en su Escuela de composición y que, por cierto, aparece en la colección madrileña en el folio 168r con el texto Laudate pueri Dominum. Lo interesante es que ambas fuentes presentan la misma letra a excepción de una palabra del primer contrapunto, que en el manuscrito aparece como "chico" y en el libro de Eslava como "niño". Sin embargo, la música varía bastante, pasando del Sol $\mathrm{m}$ en el manuscrito al La m del tratado, aunque la mayor diferencia es en la línea melódica, puesto que está variada y con bastante más adorno en Eslava. Por tanto, todo ello apunta a que este último tomó una versión popular del canon, sin tener acceso a fuentes antiguas, lo que también indica el hecho de que, como se ha visto, Eslava señale "que dicen ser compuesto por el distinguido literato D. Tomas de Yriarte". 
Tras describir el importante manuscrito de cánones del Conservatorio Superior de Música de Madrid, debemos señalar que existe una fuente mucho más completa con obras de Iriarte de este mismo género, que es la que queremos dar a conocer en el presente trabajo de investigación. En concreto, la fuente está ubicada en un archivo particular cuyo depositario, por expreso deseo, quiere permanecer en el anonimato; no obstante, aprovechamos esta ocasión para agradecerle que nos hiciese llegar una copia de la misma y permitir su estudio y publicación.

El soporte de los Cánones es el papel manuscrito, con un tamaño ligeramente superior al A4. Estos folios están cosidos con hilo por el lado izquierdo de los mismos, resultado así un cuadernillo. En total la fuente consta de catorce folios sin numerar, pero cuya secuencia utilizamos en este trabajo para poder referirnos a cada sitio. También se caracteriza por presentar cierta calidad de papel, lo que permite escribir en sus dos caras aunque apareciendo transparencias en algunas ocasiones. Igualmente, apuntamos que la calidad del papel ha posibilitado que la fuente presente un buen estado de conservación en la actualidad, con todos los folios completos a excepción del primero. Además, este folio del comienzo, que es la portada, no está incompleto por el paso del tiempo, sino que en algún momento fue cortado longitudinalmente en su lado inferior.

En la portada se recoge el título "Canones a 3 y a 4 voces / por $\mathrm{D}^{\mathrm{n}}$. Tomas Yriarte / Requiescant in pace", seguido de una rúbrica en forma de espiral que es la misma que aparece al final del folio $14 r$, aunque en esta última ocasión tras el vocablo latino "finis". De esto podemos deducir no solo la autoría de las obras, sino también que la fuente es posterior al fallecimiento de Tomás de Iriarte en septiembre de 1791 y, posiblemente, cercana a este por introducir el "Requiescant in pace". De igual forma, el hecho de que aparezca la misma rúbrica en la portada y después, señalando la finalización, otorga homogeneidad al contenido del cuadernillo, lo que se apoya también en que la mayor parte de los cánones siguen una numeración consecutiva. Por último, de la portada hay que señalar cómo en el ángulo superior derecho aparece un nombre en diferente tinta con su rúbrica, "Jose $\mathrm{M}^{\mathrm{a}}$. Velasco", del que no hemos hallado información hasta el momento.

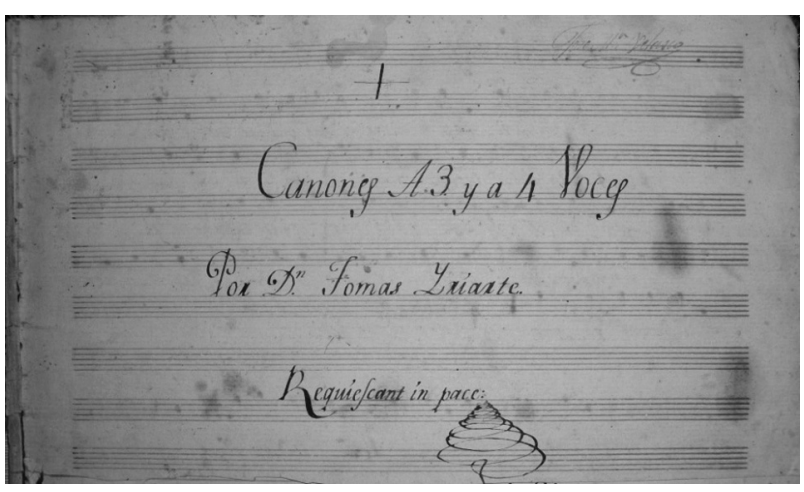

Fig. 2: Cánones de Tomás de Iriarte. Archivo Privado, fol. 1r.
El documento presenta cánones a varias voces, todos "perpetuos" según la definición que ya se ha visto de Eslava, lo que se señala en ellos mediante la indicación DC. En el fol. 1v aparece el epígrafe "Canones a 3 vozes", tras lo que se incluyen diecinueve piezas numeradas consecutivamente, conteniendo cada folio una o dos de estas dependiendo de la extensión de las mismas. Después, en el folio 9r se recoge el epígrafe "Canones a quatro voces", con catorce cánones numerados consecutivamente desde el uno, distribuidos uno, dos o tres por folio según la longitud.

En este último epígrafe hay algunas excepciones, siendo la primera de ellas que en el folio $13 \mathrm{r}$ el canon décimo no tiene numeración alguna, pero es contabilizado en el orden general; además, se trata de una obra que, tal y como se señala antes de la misma, "La danza prima a quatro voces y se puede cantar a ocho entrando a los dos compases". Pero la más importante de las excepciones es la aparición de otras dos piezas a tres voces, la primera de ellas en el folio 10r y la otra en su cara vuelta. Dichos dos cánones presentan una grafía distinta a la de resto de los existentes entre la portada y la rúbrica "Finis" del folio $14 \mathrm{r}$ y, además, no tienen número de orden alguno, lo que parece indicar que se añadieron con posterioridad a la colección. Por tanto, estos dos cánones podrían atribuirse a Tomás de Iriarte al haber sido introducidos en la colección sin ninguna anotación que lo niegue, pero hasta que no aparezca una nueva fuente que lo confirme o desmienta lo más adecuado es plantear su autoría solo como hipótesis.

Una vez terminado el epígrafe de los "Canones a quatro voces", en el folio $14 \mathrm{r}$ se recogen dos nuevas obras antes del "Finis", con la misma grafía general de la colección aunque sin numerar: la primera de ellas es un "Canon a 3 voces"; y la segunda un "Canon a 2 vozes". Para finalizar, el cuadernillo contiene en el folio $14 \mathrm{v}$ las dos mismas obras que ya aparecían en los folios $10 \mathrm{r}$ y $10 \mathrm{v}$ y, además, la grafía también coincide, aunque ahora con una escritura más rápida. Por ello, es posible que estos últimos cánones sirviesen de borradores para los anteriores del mismo título y escritura cuidada, sobre todo si se tiene en cuenta que la penúltima obra está en la tonalidad de La M y cuando aparece antes lo hace en Sol M, es decir, transportada una segunda mayor descendente-que favorece la interpretación de las notas agudas con las que cuenta y evita bastantes alteraciones-. En resumen, la fuente que presentamos en este trabajo contiene nada menos que treinta y siete cánones diferentes más dos repetidos, frente a los solo diecisiete de la colección del Conservatorio de Madrid, con las coincidencias que se recogen por orden alfabético en la siguiente tabla y que, por tanto, confirman aún más la autoría de Iriarte: 
Tabla: Cánones que comparten la colección del Conservatorio de Madrid y la nueva fuente

\begin{tabular}{|l|c|c|}
\hline \multicolumn{1}{|c|}{$\begin{array}{c}\text { Comienzo del texto } \\
\text { normalizado }\end{array}$} & $\begin{array}{c}\text { Fuente } \\
\text { Conservatorio } \\
\mathbf{n}^{\mathbf{0}} \mathbf{d e} \text { folio }\end{array}$ & $\begin{array}{c}\text { Fuente } \\
\text { Privada } \\
\mathbf{n}^{\mathbf{d}} \mathbf{\text { de }} \\
\text { folio }\end{array}$ \\
\hline Allá en la América & $168 \mathrm{v}$ & $5 \mathrm{v}$ \\
\hline Ahora que al sueño te rindes & $167 \mathrm{r}$ & $2 \mathrm{r}$ \\
\hline Aprended compañeros a imitar & $167 \mathrm{r}$ & $3 \mathrm{v}$ \\
\hline Contradanza abierta a todos & $167 \mathrm{v}$ & $7 \mathrm{r}$ \\
\hline Cuando yo te quería & $170 \mathrm{v}$ & $9 \mathrm{v}$ \\
\hline Cuatro voces al oído embelesan & $172 \mathrm{r}$ & $11 \mathrm{r}$ \\
\hline Dices que no me quieres & $170 \mathrm{r}$ & $12 \mathrm{v}$ \\
\hline El bonete del cura & $170 \mathrm{v}$ & $9 \mathrm{v}$ \\
\hline El claro arroyuelo & $168 \mathrm{r}$ & $8 \mathrm{r}$ \\
\hline Fuego, fuego, fuego & $167 \mathrm{v}$ & $8 \mathrm{r}$ \\
\hline Laudate pueri Dominum & $168 \mathrm{r}$ & $6 \mathrm{v}$ \\
\hline Para hacer bien y decir misas & $169 \mathrm{r}$ & $7 \mathrm{v}$ \\
\hline Porque ves que te quiero & $170 \mathrm{r}$ & $12 \mathrm{v}$ \\
\hline Una vez que te vi en las eras & $169 \mathrm{v}$ & $1 \mathrm{v}$ \\
\hline Una vieja comió seis besugos & $171 \mathrm{r}$ & $9 \mathrm{r}$ \\
\hline Válgame Nuestra Señora & $172 \mathrm{v}$ & $13 \mathrm{r}$ \\
\hline
\end{tabular}

El único canon de la colección del Conservatorio que no aparece en la nueva fuente presentada es el de texto Pastorcillos de la selva, el número quince de la fuente madrileña, situado en el folio $171 \mathrm{v}$ de la misma.

Todos los cánones de la nueva colección hallada constan también de una parte vocal con texto que, evidentemente, puede considerarse doble, triple o cuádruple dependiendo del número de entradas de voces o contrapuntos añadidos a la frase principal hasta un total de ocho en uno de los casos-. Lo interesante es que todas las partes vocales del documento están escritas en clave de Do en $1^{\text {a }}$ línea, a diferencia de la clave de Sol en $2^{\mathrm{a}}$ que ya dijimos se utilizaba en la colección del Conservatorio de Madrid, lo que parece otorgar una mayor antigüedad a la nueva fuente hallada. En cuanto al texto, queremos señalar que las dos fuentes son iguales a excepción de unas pocas palabras, como por ejemplo que un canon de la madrileña empiece con "Allá en la América cerca de México" y el de la nueva fuente sea "Allá en América cerca de México". Además, del texto también es interesante recordar que en la colección de Madrid el canon Laudate pueri Dominum tiene un primer contrapunto que empieza con "Un chico", lo mismo que aparece en la fuente descubierta, a diferencia del libro de Hilarión Eslava que presenta el texto "un niño": esto prueba un origen común de las dos colecciones y que Eslava toma una fuente más popular y, posiblemente, ni siquiera escrita.

Al igual que en la fuente del Conservatorio de Madrid, la nueva que damos a conocer presenta después de cada una de las partes vocales otra de "baxo" sin texto, para ser repetida las veces necesarias hasta que finalicen las voces, a excepción de los cinco últimos cánones anteriores a la rúbrica de "Finis" que carecen de ella. El hecho de no llevar texto, de que la extensión vaya del Re1 al Re3 según el sistema franco-belga de índices acústicos y de que abunden los valores largos e intervalos amplios, parece indicar que esta parte de "baxo" está compuesta para interpretarse instrumentalmente, al igual que ya apuntamos describiendo la fuente del Conservatorio madrileño. Sin embargo, resulta significativo que en esta última colección se identifique a esta parte con la palabra "bajo", frente al "baxo" más antiguo de la nueva fuente presentada en este estudio.

Para terminar, con el objetivo de describir todo el contenido de la colección que damos a conocer en este trabajo y servir para cotejar posibles nuevos hallazgos, adjuntamos un anexo con una sencilla catalogación de cada uno de los cánones debido a la limitada extensión de este artículo. El catálogo presenta las obras por orden de aparición en la fuente original, con los campos de número de folio, comienzo del texto normalizado, indicación agógica deshaciendo las abreviaturas, tonalidad, compás, número de voces y existencia de bajo, observaciones en el caso de necesitar hacerlas y, finalmente, íncipit. De este catálogo se desprende que Tomás de Iriarte utilizó sobre todo tonalidades mayores en la composición, pues estas se hallan en treinta y uno de los treinta y siete cánones distintos, destacando especialmente las tonalidades de Fa M y Sol M, seguidas de las de Mib M y Do M. También es destacable su predilección por los movimientos ligeros, sobre todo el Allegretto y, después, el Andante. Sin embargo, la colección de cánones presenta mayor homogeneidad en cuanto a los compases, con un número parecido de $4 / 4,3 / 4,2 / 4$ y $6 / 8$, seguidos poco después del $3 / 8$ y el $2 / 2$.

\section{CONCLUSIONES}

Tomás de Iriarte ha pasado a la historia española principalmente como literato y, en cuanto al arte de los sonidos, sobre todo por su poema La música, de 1779. Sin embargo, también desarrolló una interesante actividad como intérprete, principalmente de viola y violín en los conciertos o "academias armónicas" que organizaban las casas nobiliarias de la época. Además, su formación musical le permitió componer algunas obras que, a excepción de la música para su melólogo Guzmán el Bueno y un canon a tres voces recogido por Eslava en uno de sus tratados, se creían perdidas. No obstante, hace menos de una década se publicó una colección de diecisiete cánones del compositor hallados en el Conservatorio Superior de Música de Madrid, pero ahora se demuestra que la composición de cánones por parte de Iriarte fue aún mayor. Así, con este artículo se da a conocer la existencia de una colección de dicho género mucho más completa, presentando también rasgos de mayor antigüedad. Se trata de una fuente que engloba todas las obras de la colección del Conservatorio de Madrid a excepción de una y que, lo más interesante, recoge una veintena más de cánones inéditos de Iriarte, casi todos a tres y cuatro voces. En definitiva, con este trabajo de investigación se recupera un importante patrimonio musical debido a la notoriedad de su compositor, que enriquece el repertorio musical que puede ser interpretado. 


\section{BIBLIOGRAFÍA}

Aguirre, Antonio (seudónimo de Raymond Foulché-Delbosc): "La notice de Carlos Pignatelli sur Thomas de Yriarte", Revue Hispanique, 36/89 (París, 1916): 200-252.

Coralelo y Mori, Emilio: Iriarte y su época. Madrid, Sucesores de Ribadeneyra, 1897.

Eslava y Elizondo, Miguel Hilarión: Escuela de composición. Tratado segundo. Del contrapunto y fuga. Madrid, s.n., 1864, (2 $2^{\mathrm{a}}$ ed.).

Fernández Madrid, María Teresa y Gómez Lorente, Manuel: "El convento de Nuestra Señora de la Salceda. Análisis histórico y simbólico", Wad-Al-Hayara, 19 (Guadalajara, 1992): 431-444.

González del Castillo, Juan: Hannibal. [Sevilla], Imprenta de Vázquez e Hidalgo, 1791.

Iriarte Nieves-Ravelo, Tomás de: Hacer que hacemos. Madrid, Imprenta Real de La Gazeta, 1770.

Iriarte Nieves-Ravelo, Tomás de: La música. Madrid, Imprenta Real de La Gazeta, 1779.

Iriarte Nieves-Ravelo, Tomás de: Fábulas literarias. Barcelona, Imprenta de Eulalia Piferrer, 1782.

Iriarte Nieves-Ravelo, Tomás de: Guzmán el Bueno. Escena trágica unipersonal con música en sus intervalos, edición con estudio preliminar de Juan Antonio Alonso Cuesta y José Pallarés Moreno. Algeciras, Instituto de Estudios Campogibraltareños, 1999.

Iriarte Nieves-Ravelo, Tomás de: Cánones de don Tomás de Iriarte a tres y cuatro voces más bajo, transcripción y arreglo de Víctor Pliego de Andrés. Madrid, s.n., 2008.

Iriarte Nieves-Ravelo, Tomás de: Cánones de don Tomás de Iriarte a tres y cuatro voces más bajo, transcripción y arreglo de Víctor Pliego de Andrés. Madrid, Musicalis, 2009.

Martín Moreno, Antonio: Historia de la música española 4. Siglo XVIII. Madrid, Alianza, 1985.

Pérez Martínez, Vicente: Prontuario del canto llano gregoriano, corregido todo del mal acento y otros defectos notados en los libros antiguos. Madrid, Imprenta Real, 1799.

Rousseau, Jean-Jacques: Pygmalion. Strasbourg, Heitz, 1771.

Suárez Pajares, Javier: "Iriarte, Tomás", en Emilio Casares Rodicio (dir.), Diccionario de la música española e hispanoamericana. Madrid, Sociedad General de Autores y Editores, vol. VI, 2000: 471-477.

Subirá Puig, José: El compositor Iriarte (1750-1791) y el cultivo del melólogo (melodrama). Barcelona, Consejo Superior de Investigaciones Científicas, 1949, 2 vols.

\section{ANEXO: CATALOGACIÓN DE LA NUEVA FUENTE CON CÁNONES DE TOMÁS DE IRIARTE.}

Fol. 1r. Portada.

Fol. 1v. Una vez que te vi en las eras, Allegro, Re m, 6/8, 3 Voces y Bajo. Observaciones: Viene precedido por el texto " $\mathrm{Ca}$ nones a 3 vozes".
Íncipit:

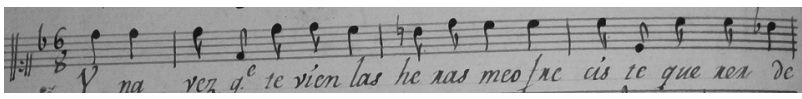

Fol. 2r. Ahora que al sueño te rindes, Minuetto, Mib M, 3/4, 3 Voces y Bajo. Observaciones: Incluye la indicación dinámica "Sotto voce".

Íncipit:

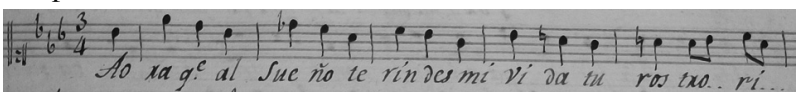

Fol. 2v. Por qué ha de ser tan tierno, Adagio maestoso, Re M, 4/4, 3 Voces y Bajo.

Incipit:

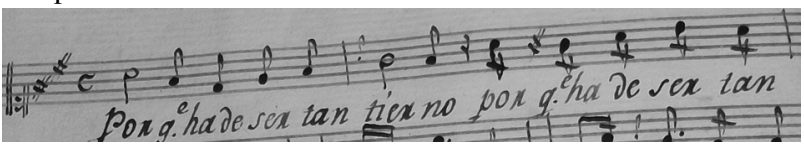

Fol. 3r. Por qué ha de ser tan tierno, Allegretto, Re M, 2/4, 3 Voces y Bajo. Observaciones: Viene precedido del texto "Con la misma letra pasada".

Íncipit:

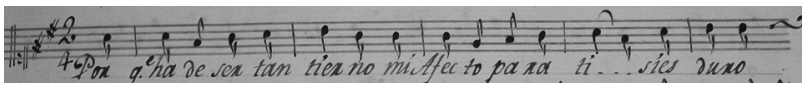

Fol. 3v. Aprended compañeros a imitar, Andante, Fa M, 3/4, 3 Voces y Bajo.

Íncipit:

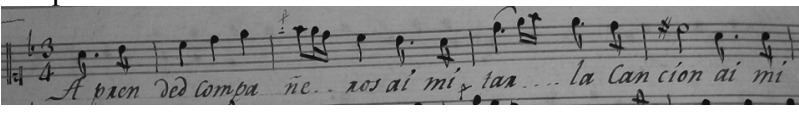

Fol. 4r. Abre la puerta divina tuerta, Andante, Sol M, 2/2, 3 Voces y Bajo.

Íncipit:

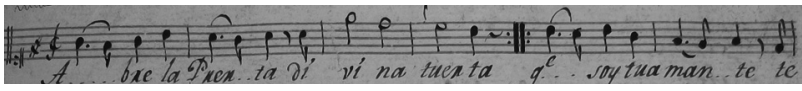

Fol. 4r. Tres martillos de herrero, Allegretto, Fa M, 3/8, 3 Voces y Bajo.

Íncipit:

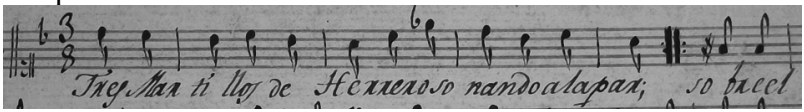

Fol. 4v. Cuando Dios crió al erizo, Andante, La M, 3/8, 3 Voces y Bajo. Observaciones: Incluye la indicación "Tirana". Íncipit:

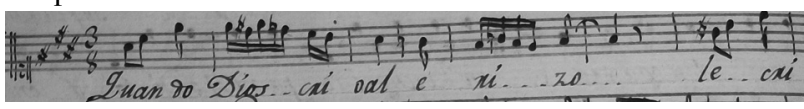

Fol. 5r. Hermoso dueño apiádate, Adagio espressivo, Sol m, 6/8, 3 Voces y Bajo.

Incipit:

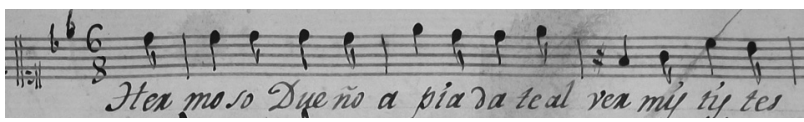


Fol. 11v. Ay Isabel cuántas moscas, Allegretto, Do M, 3/4, 4 Voces y Bajo.

Incipit:

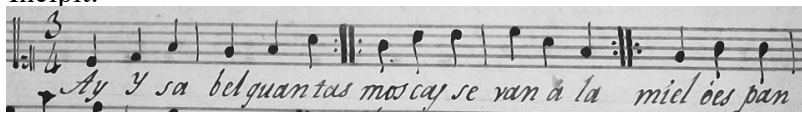

Fol. 12r. Mari, quita, Andante, Mi m, 2/4, 4 Voces y Bajo.

Íncipit:

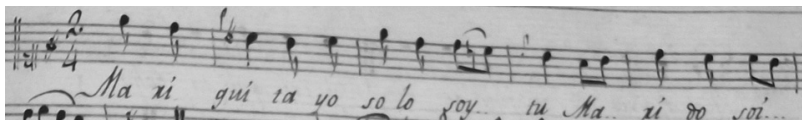

Fol. 12v. Porque ves que te quiero, Allegretto, Sol M, 6/8, 4 Voces y Bajo.

Incipit:

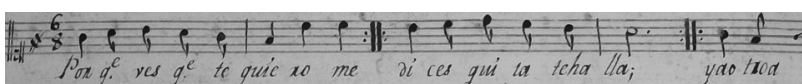

Fol. 12v. Dices que no me quieres, Allegretto, Sol M, 6/8, 4 Voces y Bajo. Observaciones: Incluye la indicación "Seguidillas". Íncipit:

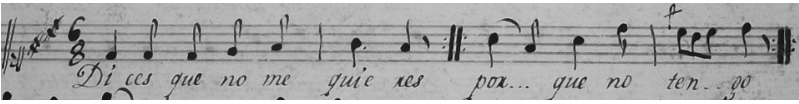

Fol. 13r. Válgame Nuestra Señora, Andante, Mib M, 4/4, 4 Voces y Bajo. Observaciones: Viene precedido por el texto " $\mathrm{La}$ Danza Prima a quatro voces y se puede cantar a ocho entrando a los dos compases".

Íncipit:

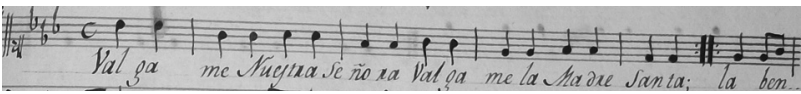

Fol. 13v. Las polainas de Juan Blanco, Andantino, Mib M, 3/8, 4 Voces.

Íncipit:

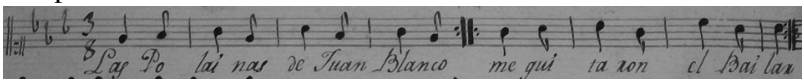

Fol. 13v. Tórtola amada, Andante amoroso, La m, 2/4, 4 Voces. Incipit:

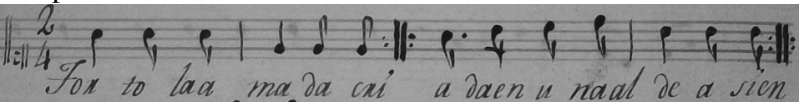

Fol. 13v. Me canso ya de solfear, Allegretto, Do M, 2/4, 4 Voces.

Íncipit:

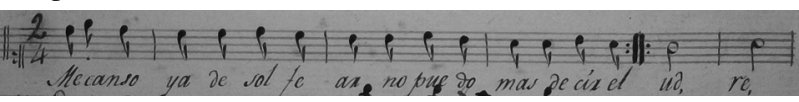

Fol. 14r. Dile a mi dulce dueño, Despacio, Re m, 6/8, 3 Voces. Observaciones: Viene precedido por el texto "Canon a 3 voces". Íncipit:

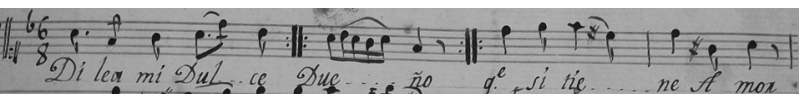

Fol. 14r. El cura y el sacristán, Andantino, Fa M, 4/4, 2 Voces. Observaciones: Viene precedido por el texto "Canon a 2 vozes" y termina con "Finis".

Incipit:

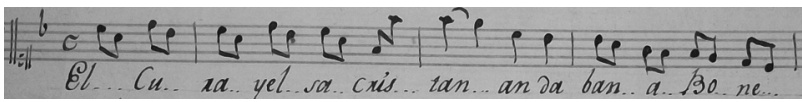

Fol. 14v. Por qué prenda querida, Larguetto, La M, 3/4, 3 Voces y Bajo. Observaciones: En el fol. 10v se repite en Sol M. Incipit:

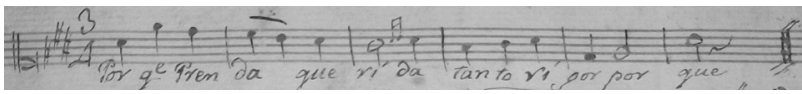

Fol. 14v. Qué pena, qué afanes, Andante, Sol M, 4/4, 3 Voces. Observaciones: En el fol. 10r se repite con Bajo.

Incipit:

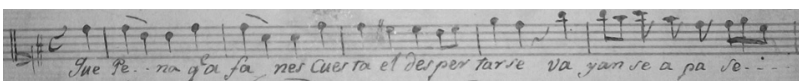

Recibido: 14.04 .2018

Aceptado: 16.04.2018 